\title{
LEVANTAMENTO PARTICIPATIVO E FORMAÇÃO CONTINUADA SOBRE PLANTAS MEDICINAIS CULTIVADAS NO MUNICÍPIO DE SERRARIA-PB
}

\section{PARTICIPATORY SURVEY AND ONGOING TRAINING ON MEDICINAL PLANTS GROWN IN THE MUNICIPALITY OF SERRARIA-PB}

Juliana Ferreira de Lima ${ }^{1}$; João Gomes de Oliveira Neto ${ }^{1}$; Alexandre Eduardo de Araújo ${ }^{2}$; Dalila Alves da Silva ${ }^{3}$; José Tavares de Freitas ${ }^{4}$.

${ }^{1}$ Universidade Federal da Paraíba, Campus III, S/N. Mestres em Ciências Agrárias (Agroecologia), e-mails: julianacavnufpb@ hotmail.com; j.dalila.neto@gmail.com; ${ }^{2}$ Professor da UFPB/CCHSA, Campus III, alexandreeduardodearaujo@ hotmail.com; ${ }^{3}$ Nutricionista pela Universidade Católica de Brasília-DF, e-mail: Alves.dalila@gmail.com; ${ }^{4}$ Bacharelando em

Agroecologia UFPB/CCHSA, Campus III, Bananeiras - PB. tavareshoffman@gmail.com. DOI: https://doi.org/10.52719/bjas.v1i2.2886

\section{RESUMO}

As plantas medicinais podem ser utilizadas como uma alternativa ou de forma complementar para os tratamentos medicinais convencionais, sendo este conhecimento transmitido ao longo das gerações de pais para filhos, valorizando-se assim os conhecimentos tradicionais dos antepassados. Este trabalho foi desenvolvido no mês de abril de 2018 no município de Serraria, e, o objetivo do estudo foi fazer um levantamento sobre o conhecimento e uso de plantas medicinais por agricultores familiares do município de Serraria-PB. A atividade foi dividida em 3 etapas: ${ }^{1}$ levantamento participativo das principais plantas medicinais utilizadas pelos agricultores da Comunidade Matinha, Zona Rural de Serraria-PB; ${ }^{2}$ confecção de folhetim informativo com informações das plantas identificadas na etapa anterior; ${ }^{3}$ Atividade de formação continuada (oficina) sobre produção e uso de plantas medicinais com agricultores, agricultoras e jovens agricultores participantes da Feira da Agricultura Familiar de Serraria-PB (FAFS) e representantes de equipe de produção e comercialização de flores, além de dois estudantes do programa de Pós Graduação em Ciências Agrárias (Agroecologia) da UFPB, Campus III que atuaram como facilitadores. Foram produzidas 200 mudas de plantas medicinais a partir da técnica da estaquia, além da socialização de diversos saberes locais. As plantas medicinais se constituem em uma importante estratégia para as famílias rurais no que diz respeito a economia na aquisição de remédios, podendo ser uma fonte de renda extra quando comercializadas em feiras ou demais pontos de comercialização, tendo como um de seus maiores benefícios a acessibilidade em seus quintais e hortas, a toda hora, sem gastos adicionais.

Palavras-chave: Agroecologia. Conhecimento local. Resgate. 


\begin{abstract}
Medicinal plants can be used as an alternative or complementary to conventional medicinal treatments, and this knowledge is passed on through generations of parents to children, thus valuing the traditional knowledge of ancestors. This study was developed in April 2018 in the municipality of Serraria, and the objective of the study was to make a survey about the knowledge and use of medicinal plants by family farmers in the municipality of Serraria-PB. The activity was divided into 3 stages: particip Participatory survey of the main medicinal plants used by the farmers of Matinha Community, Rural Zone of Serraria-PB; ${ }^{2}$ preparation of information leaflet with information of plants identified in the previous step; ${ }^{3}$ Continuous training activity (workshop) on production and use of medicinal plants with farmers, farmers and young farmers participating in the Serraria-PB Family Farming Fair (FAFS) and representatives of flower production and marketing team, as well as two students from the Graduate program in Agricultural Sciences (Agroecology) of UFPB, Campus III that acted as facilitators. 200 seedlings of medicinal plants were produced from the cutting technique, in addition to the socialization of various local knowledge. Medicinal plants are an important strategy for rural families with regard to the economy in the purchase of medicines, and can be a source of extra income when marketed at fairs or other points of sale, having as one of their greatest benefits accessibility. in your backyards and vegetable gardens, all the time, at no extra cost.
\end{abstract}

Keywords: Agroecology. Local knowledge. Rescue.

\title{
1 INTRODUÇÃO
}

De acordo com Berg (1987), a utilização de plantas medicinais caseira, é praticada desde os primórdios da civilização humana. Na pré-história, o homem procurava amenizar suas dores ou tratar suas moléstias através da ação dos princípios ativos existentes nos vegetais, embora de modo totalmente empírico ou intuitivo baseado em descobertas ao acaso. Essa conduta pode, ainda, ser observada entre os povos primitivos, isolados, como algumas tribos indígenas da América do Sul.

Segundo Lameira e Pinto (2008): "No Brasil, as primeiras referências sobre plantas medicinais são atribuídas ao padre José de Anchieta e a outros jesuítas que aqui viveram durante os tempos coloniais, sendo bastante utilizadas pelos indígenas que transmitiram as informações para imigrantes europeus e escravos africanos. Essa utilização pelos negros, durante cem anos 

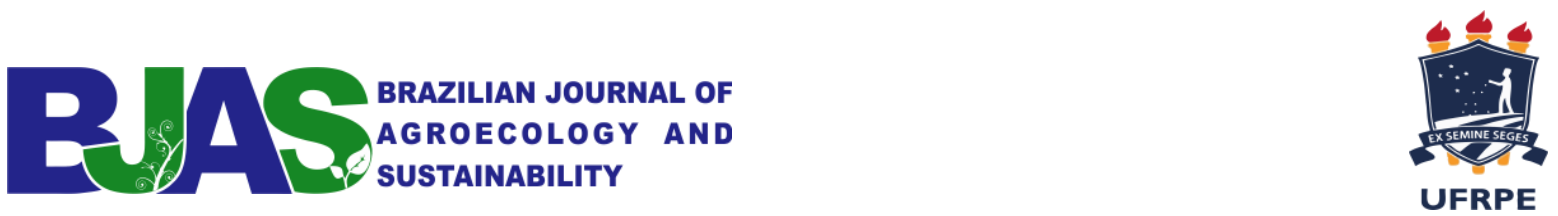

no movimento dos quilombos, concorreu fortemente para o estabelecimento de uma rica medicina popular."

Matos (1987) relata que da década de 50 até a década de 70, as plantas medicinais foram marginalizadas devido à asceção da química orgânica que promoveu a medicina alelopática, contudo a partir a partir da década de 80 , ouve uma revalorização desse conhecimento popular como fonte de propriedades curativas de baixo custo.

As plantas medicinais têm uma importância social econômica e ambiental. No aspecto social, têm papel fundamental para as populações menos favorecidas. No Brasil, como em muitas outras partes doo mundo, a medicina fitoterápica é praticada tanto por curandeiros populares, para os quais a prática da fitoterapia é parte integral da cultura tradicional, quanto por fitoterâupetas profissionais. (Lameira \& Pinto, 2008).

No aspecto econômico há um expressivo mercado mundial dos medicamentos fitoterápicos. Sendo também importante para os tratamentos alternativos para populações rurais, povos tradicionais, e para quem busca um tratamento mais natural para algumas enfermidades, sendo uma alternativa de medicamentos de baixo custo e de fácil manutenção.

Já no aspecto ambiental, como relata Pimentel (1994): “As plantas são ao mesmo tempo prisioneiras e modeladoras de seu meio ambiente. A solução para encontrar uma determinada espécie é conhecer as condições ambientais e o habitat mais favorável a ela." Sendo assim, quanto mais biodiverso o habitat mais planta com princípios medicinais é possível identificar e assim, analisar suas possíveis propriedades terapêuticas.

A conservação de ecossistemas naturais é importante para identificação de plantas medicinais e suas possíveis formas de usos, pois de acordo com Lameira e Pinto (2008), a exploração de plantas de uso medicinal da flora nativa, através da extração direta (extrativismo), tem levado a redução dessas espécies, sendo importante o incentivo de suas multiplicações a partir da domesticação e posterior cultivo em quintais ou hortos medicinais comunitários.

Ainda de acordo com Lameira e Pinto (2008), o cultivo racional de plantas medicinais é uma etapa primordial, uma vez que estas não requerem grandes áreas, nem dependem de custos elevados para suas implantações, sendo uma alternativa de cultivo para quintais urbanos e rurais. 

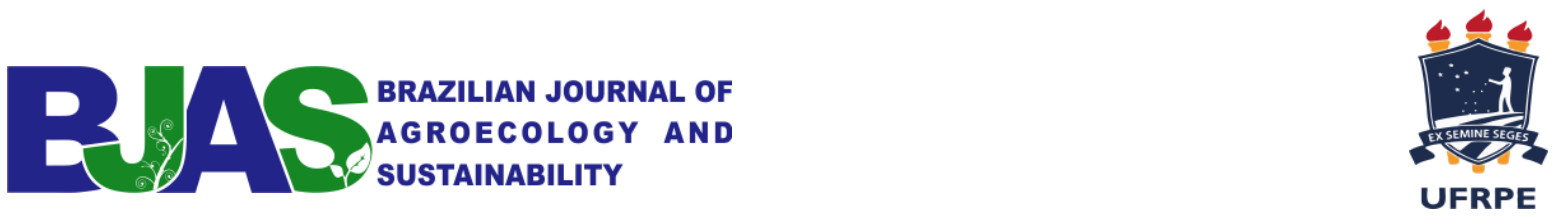

As plantas medicinais podem ser utilizadas como uma alternativa ou complementar para tratamentos medicinais convencionais, conhecimento transmitido ao longo das gerações de pais para filhos, valorizando-se assim os conhecimentos tradicionais dos antepassados.

No Brasil existem diversidades e peculiaridades, com concepções, opiniões, valores, conhecimentos, práticas e técnicas diferentes, que precisam ser incorporadas e respeitadas no cotidiano, influenciadas por hábitos, tradições e costumes. O conhecimento e uso das plantas medicinais têm sido estimados, baseando em algumas variáveis sociais. (Nogueira, 1983)

Segundo a Resolução da Diretoria Colegiada n 48/2004 da Agência Nacional de Vigilância Sanitária [ANVISA] (2004) “fitoterápicos são medicamentos preparados exclusivamente com plantas ou partes de plantas medicinais (raízes, cascas, folhas, flores, frutos ou sementes), que possuem propriedades reconhecidas de cura, prevenção, diagnóstico ou tratamento sintomático de doenças, validadas em estudos etnofarmacológicos, documentações tecnocientíficas ou ensaios clínicos de fase 3. Com o desenvolvimento da ciência e da tecnologia as plantas medicinais estão tendo seu valor terapêutico pesquisado e ratificado pela ciência e vem crescendo sua utilização recomendada por profissionais de saúde. ”

De acordo com sua ação nos organismos as plantas medicinais podem ser classificadas segundo Arnous, Santos, \& Beinner (2005), como: estimulantes, calmantes, emolientes, fortificantes, de ação coagulante, diuréticas, sudoríferas, hipotensoras, de função reguladora intestinal, colagogas, depurativas, remineralizantes e reconstituintes.

O objetivo do estudo foi fazer o levantamento das plantas medicinais existentes nas propriedades de agricultores (as) da feira da agricultura familiar de Serraria-PB, e promover uma formação continuada sobre plantas medicinais para os agricultores do município.

\section{METODOLOGIA}

Este trabalho foi desenvolvido no mês de abril de 2018 no município de Serraria, na mesorregião do agreste paraibano e microrregião do brejo, localizado no território da Borborema, conforme classificação do Ministério do Desenvolvimento Agrário (MDA), com uma área de 65,299 km², com uma população estimada de 6.093habitantes (Instituto Brasileiro de Geográfia e Estatística [IBGE], 2018). 
A partir do levantamento realizado no Sítio Matinhas, Zona Rural do município de Serraria-PB, com 18 agricultoras (es) familiares das comunidades Matinhas, PA Campo Verde II e PA Cajazeiras. O trabalho foi dividido em 3 etapas, que serão melhor detalhadas a posterior:

1. Levantamento participativo das principais plantas medicinais utilizadas pelos agricultores da Comunidade Matinha, Zona Rural de Serraria-PB;

2. Confecção de folhetim informativo com informações das plantas identificadas na etapa anterior;

3. Atividade de formação continuada (oficina) sobre produção e uso de plantas medicinais com agricultores, agricultoras e jovens agricultores participantes da Feira da Agricultura Familiar de Serraria-PB e representantes de equipe de produção e comercialização de flores, e, dois estudantes do programa de Pós-Graduação em Ciências Agrárias (Agroecologia) da UFPB, Campus III que atuaram como facilitadores.

$\mathrm{Na}$ primeira etapa do estudo ocorreu de forma participativa, através do registro fotográfico e coleta de algumas plantas medicinais conhecidas popularmente pelos agricultores (a), a partir de uma conversa participativa entre todos. Na segunda etapa do trabalho realizouse uma pesquisa bibliográfica sobre as plantas medicinais identificadas na primeira etapa, que junto com as informações obtidas com os agricultores, subsidiou um folhetim informativo com as plantas até então identificadas. Na terceira etapa, ocorreu uma oficina para produção de mudas de algumas plantas medicinais, como estratégia de resgate e fortalecimento do conhecimento do referido assunto, além da partilha de vários conhecimentos e saberes locais por parte dos agricultores e agricultoras presentes.

Para reconhecimento, nomenclatura e identificação de formas de preparos (receitas) realizou-se uma conversa colaborativa com os agricultores e agricultoras, detentores do conhecimento empírico a respeito dessas plantas. Foi realizada a sistematização das informações obtidas e dispostas no tópico a seguir.

\section{RESULTADOS E DISCUSSÃO}

3.1 Levantamento participativo de plantas medicinais com agricultores (as) familiares do Sítio Matinhas, Serraria-PB

A partir do levantamento foram identificadas as principais plantas medicinais comuns a várias propriedades rurais, a partir de então, percebeu-se a necessidade de realizar uma atividade de multiplicação de plantas medicinais para os agricultores da feira da agricultura 

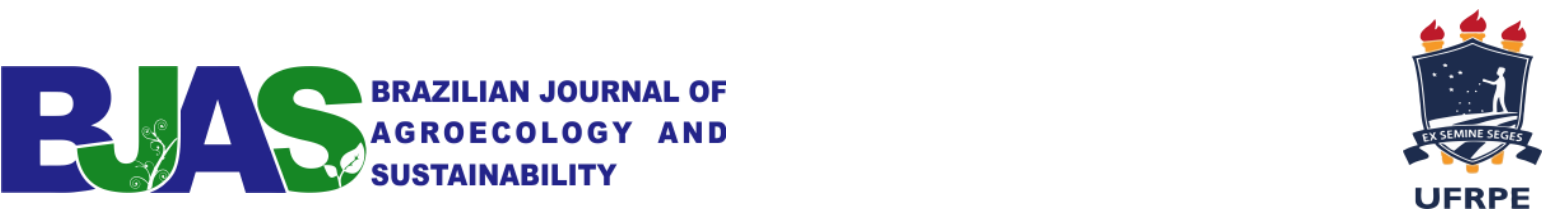

familiar de Serraria-PB, a fim de fortalecer essa dinâmica e reintroduzir alguns cultivares, podendo gerar também uma renda complementar futura a partir da comercialização das referidas plantas para chás, lambedores ou mesmo as mudas para cultivos em hortas e quintais urbanos, conforme descritas a seguir, tendo como referência informações advindas dos conhecimentos prévios dos agricultores e agricultoras familiares do perímetro rural em estudo.

\subsubsection{Arruda (Ruta graveolens L.)}

A arruda (figura 1) é originária da Europa meridional, da família da Rutaceae, tem propriedades adstringente, analgésica (reduz a dor), antiasmática, antiepiléptica, antiespasmódica (reduz contrações musculares involuntárias), anti-helmíntica (elimina vermes), anti-histérica, anti-inflamatória, antinevrálgica (redução de dores do sistema nervoso), bactericida (mata bactérias), calmante, carminativa (eliminador de gases intestinais), cicatrizante. Suas folhas são utilizadas popularmente na região na forma de chá para o tratamento de desordens menstruais, inflamações na pele, dor de ouvido, dor de dente, febre, câimbras, doenças do fígado, verminose e como abortivo.

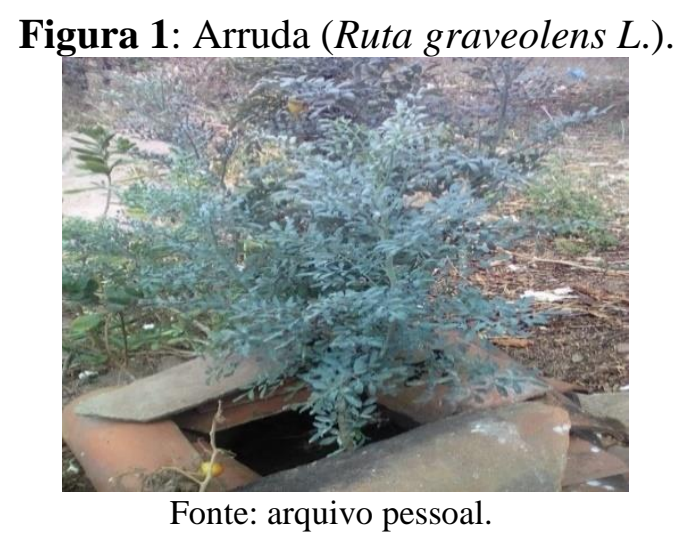

\subsubsection{Baboza (Aloe vera (L.) Burm.f.)}

A baboza (figura 2), é originária da África, da família Asphodelacea (anteriormente Liliaceae), tem propriedades Cicatrizante, antimicrobiana, emoliente (hidratante da pele). Suas folhas são utilizadas popularmente na região co

mo cicatrizantes, hidratantes para cabelos, tratamento de queimaduras, piolhos e caspas. 
Figura 2: Baboza (Aloe vera (L.) Burm. f.)

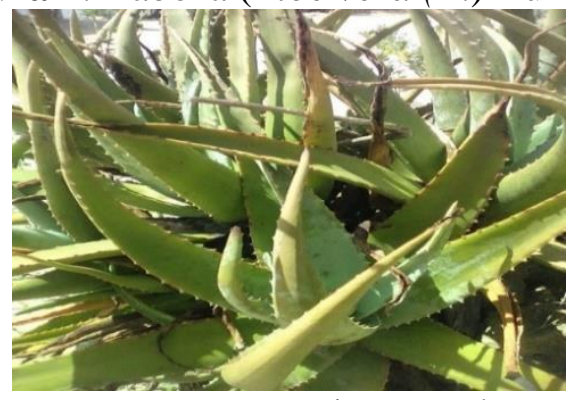

Fonte: arquivo pessoal.

\subsubsection{Boa noite branca (Catharanthus roseus)}

A boa noite branca (figura 3), encontrada em praticamente todos os terreiros visitados, pertence à família Apocynaceae (Angiospermas), é originária de Madagascar (não se tem certeza, mas isso é de acordo com indicações de estudiosos). É uma planta pantropical, no Nordeste é mais cultivada como planta ornamental para embelezar jardins. Suas flores são utilizadas, popularmente na região, maceradas e o líquido resultante desta maceração é utilizado para dor de ouvido.

Figura 3: Boa noite branca (Catharanthus roseus)

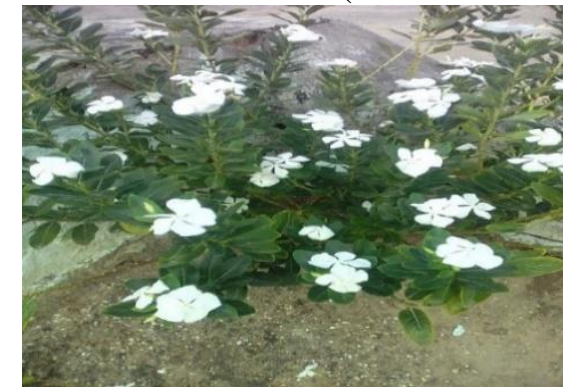

Fonte: arquivo pessoal.

\subsubsection{Capim santo (Cymbopogon citratus)}

O capim santo (figura 4), bem utilizada não apenas por agricultores, mas também por urbanos do município, é originário da Índia, da família Poaceae, tem ação calmante, analgésico (dores do estomago), digestivo, dentre outras.

É uma erva aromática anual, forma touceiras, suas folhas são eretas ou curvas. Suas folhas são utilizadas popularmente na região na forma de chá. De acordo com os conhecimentos populares, abordados pelos agricultores na oficina que será abordada a posterior, a utilização do chá de capim santo durante a gestação e lactação serve como um estimulante à lactação.

Figura 4: Capim santo (Cymbopogon citratus) 


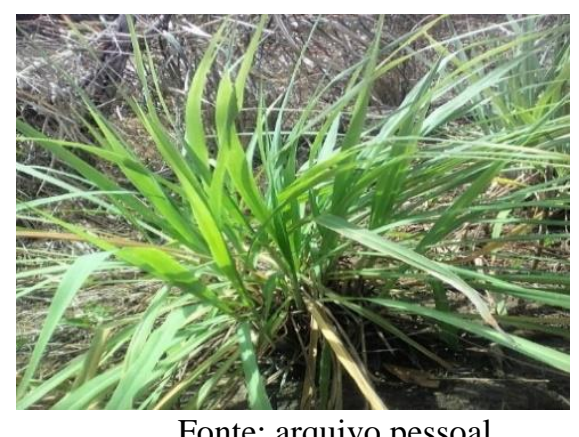

Fonte: arquivo pessoal.

\subsubsection{Erva cidreira (Melissa officinalis $L$ )}

A erva cidreira (figura 5) é originária da Europa e Ásia, da família Labiatae (Lamiaceae), tem propriedades Calmante, bacteriostática. Popularmente, suas folhas e flores são utilizadas na forma de chá como calmante nos casos de insônia e como medicação contra dispepsia, gripes, bronquite crônica, para normalizar as funções gastrintestinais, cólica menstrual, diarreia e nervosismo.

Figura 5: Erva cidreira (Melissa officinalis L)

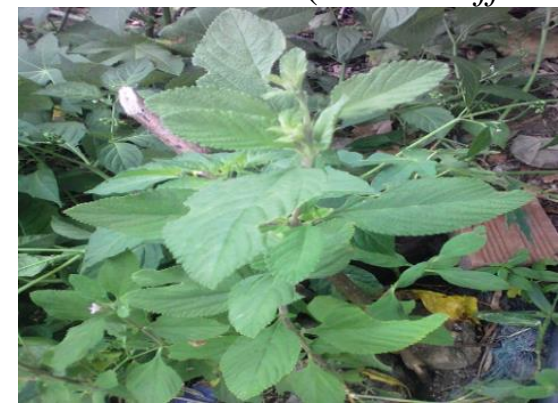

Fonte: arquivo pessoal.

\subsubsection{Hortelã da folha grossa (Plectranthus amboinicus (Lour.) Spreng)}

A hortelã da folha grossa (figura 6) originário da África, família Lamiaceae. Tem propriedades Cicatrizante, anti-inflamatório, protetor da mucosa bucal. Popularmente é utilizado para cicatrização de feridas, febre, asma, tosse, bronquite.

Figura 6: Hortelã da folha grossa (Plectranthus amboinicus (Lour.) Spreng)

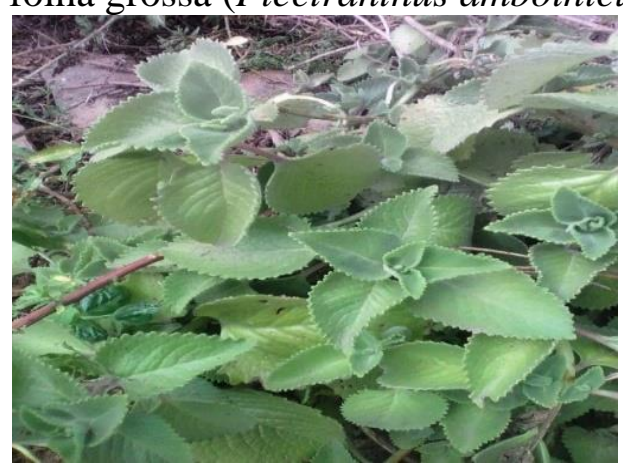

Fonte: arquivo pessoal. 


\subsubsection{Hortelã da folha miúda (Mentha villosa)}

A hortelã da folha miúda (figura 7), também usada como condimento, é uma das mais antigas plantas medicinais, originária da Inglaterra. Tem propriedades sedativa, cicatrizante e desinfetante, além de apresentar ótimos resultados para o tratamento de febre, prisão de ventre, e dores abdominais.

Figura 7: Hortelã da folha miúda (Mentha villosa)

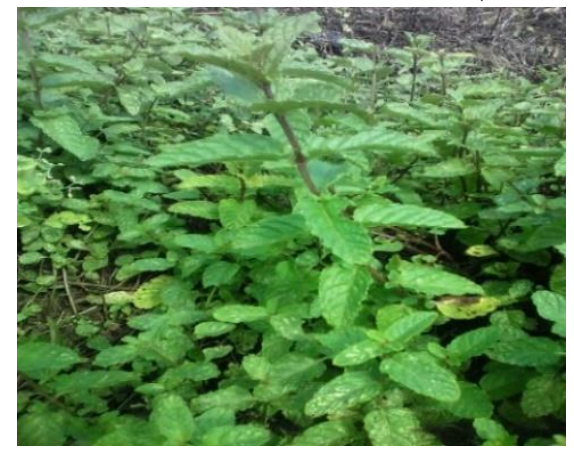

Fonte: arquivo pessoal.

\subsubsection{Mastruz (Dysphania ambrosioides)}

O mastruz (figura 8), é nativo da América Central e do Sul é da família das Amaranthaceae, contêm propriedades vermífugas, antibióticas, antifúngicas, digestivas, antioxidantes, anti-inflamatórias e cicatrizantes. É utilizado no tratamento de vermes, tem efeito expectorante nas doenças respiratórias e combate problemas digestivo.

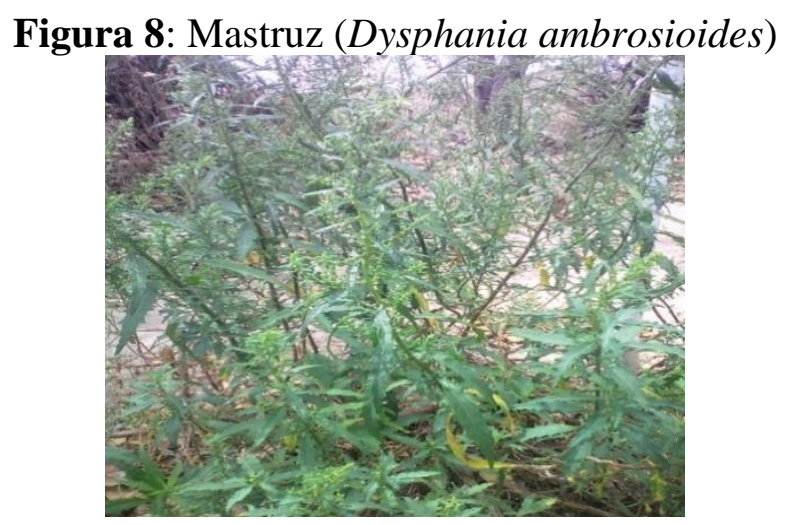

Fonte: arquivo pessoal.

\subsubsection{Quebra pedra (Phyllanthus niruri L.)}

A planta conhecida como quebra pedras (figura 9) é originária das regiões tropicais, da família Euphorbiaceae, tem propriedades diurética, aperiente (abre o apetite), analgésica, relaxante muscular, anti-infecciosa. Toda a planta é utilizada popularmente na região para o 

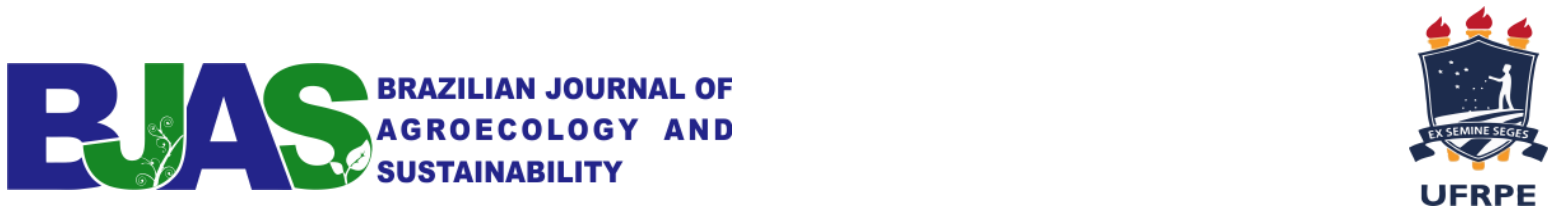

tratamento dos rins a fim de eliminar as pedras dos rins. Sendo contraindicada durante a gravidez.

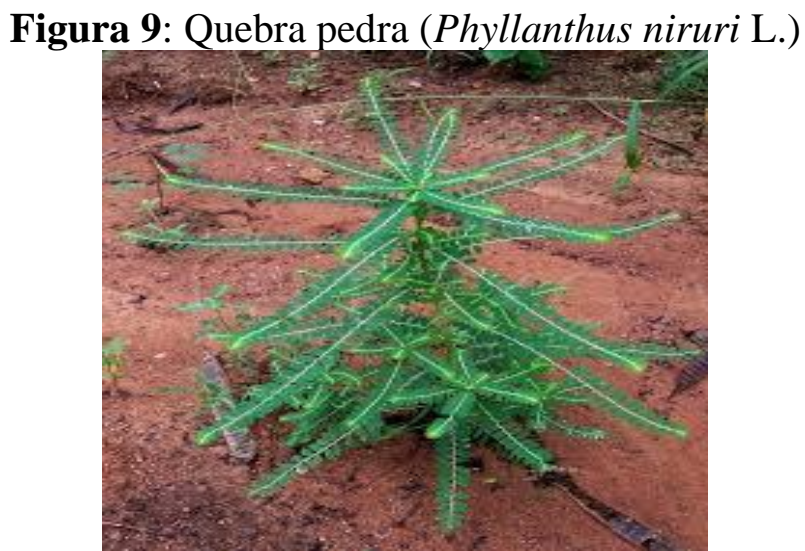

Fonte: arquivo pessoal.

\subsubsection{Romã (Punica granatum $L$ )}

A romã (figura 10) é Originária da Ásia, da família Punicaceae, tem propriedades diurético, vermífugo, antisséptico (contenção de microrganismos). Popularmente, a casca do fruto é utilizada para tratamento de inflamações na boca e na garganta. Também podem ser utilizadas a casca da árvore, raiz, caule e fruto. Sendo também utilizada como cicatrizante e antisséptico.

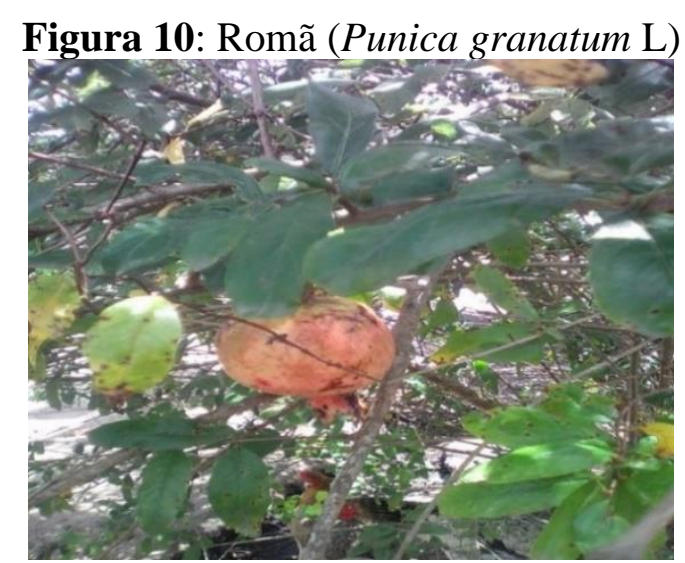

Fonte: arquivo pessoal.

\subsubsection{Sabugueiro (Sambucus nigra L.)}

O sabugueiro (figura 11), é nativo da Europa, da família Adoxaceae. É utilizado suas flores, folhas, frutos, raízes e entrecasca. O chá de sabugueiro feito com as flores desidratadas é utilizado para febres, resfriados e para eliminar o catarro. 

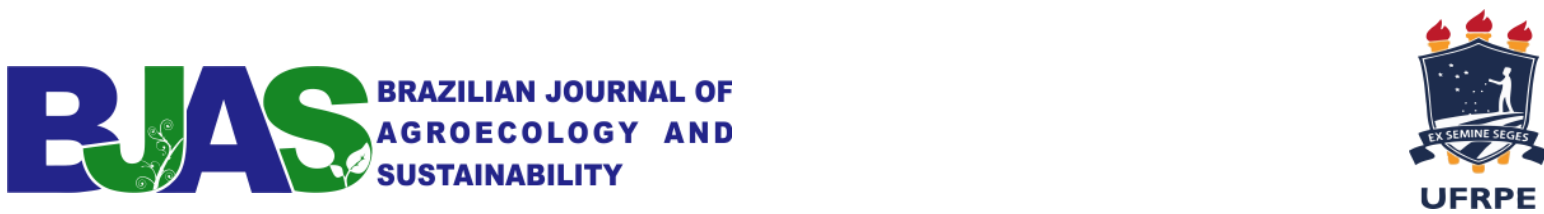

Já as raízes são utilizadas como diurético, laxativo e antirreumática. A entrecasca pode ser utilizada como cicatrizante, antisséptico e anti-inflamatório. As folhas também são utilizadas como diuréticas.

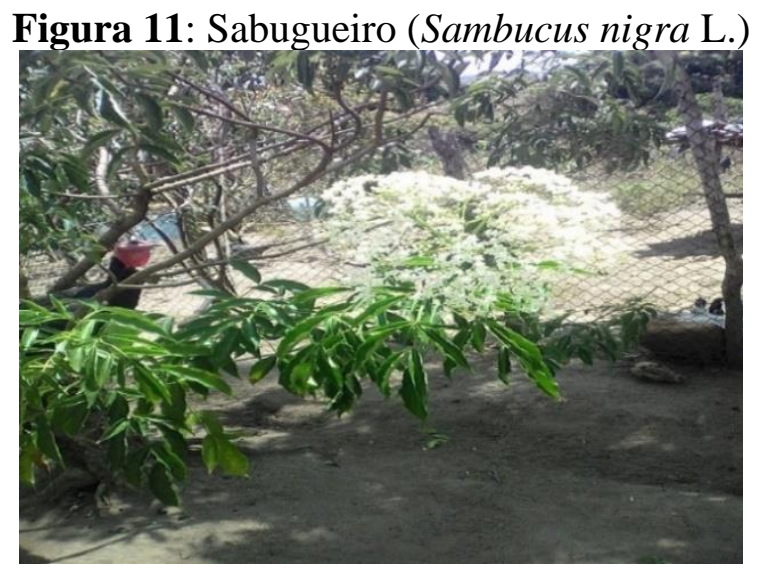

Fonte: arquivo pessoal.

\subsubsection{Manjericão menino (Ocimum basilicum)}

O manjericão menino (figura 12), também conhecido por manjericão da folha miúda, é nativo da Índia e da Ásia, família da Lamiaceae, alivia a tosse, diminuem o estresse, asmas e alergias e é utilizado em forma de chá para mulheres gestantes quando estas estão perdendo sangue evitando assim o aborto.

Figura 12: Manjericão menino (Ocimum basilicum)

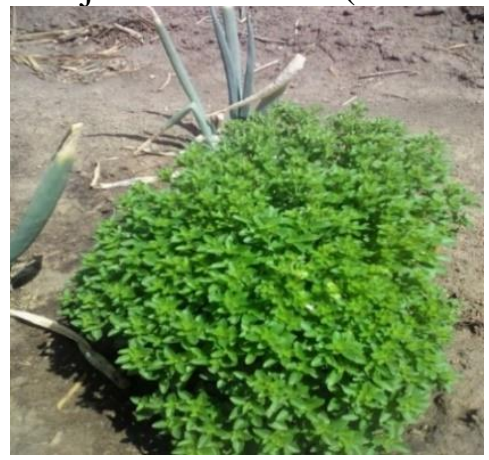

Fonte: arquivo pessoal.

\subsection{Oficina de Produção de Mudas de Plantas Medicinais}

Como resultado da pesquisa participativa confeccionou-se um folhetim informativo, conforme a figura 13. O referido material servirá como socialização da importância dessas plantas, além de ser um resgate e valorização da cultura local. Todas as informações de indicação e contraindicação constadas no folhetim informativo foram colocadas de acordo com os relatos dos agricultores e agricultoras participantes das atividades desenvolvidas em todas as etapas deste trabalho. 

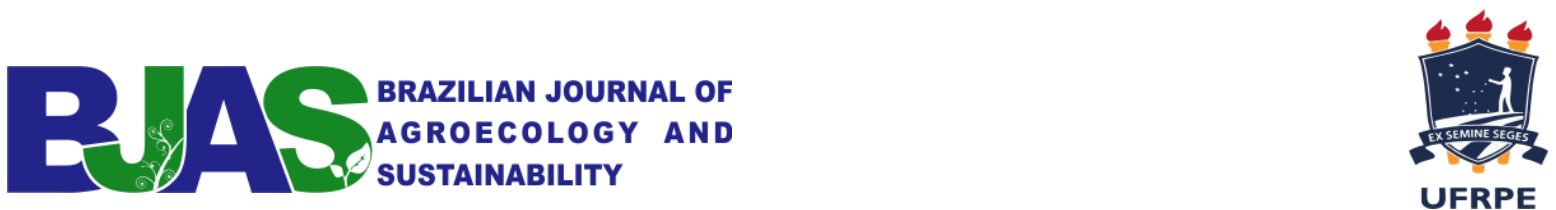

Figura 13: Folhetim informativo com plantas medicinais identificadas no Sítio Matinhas.

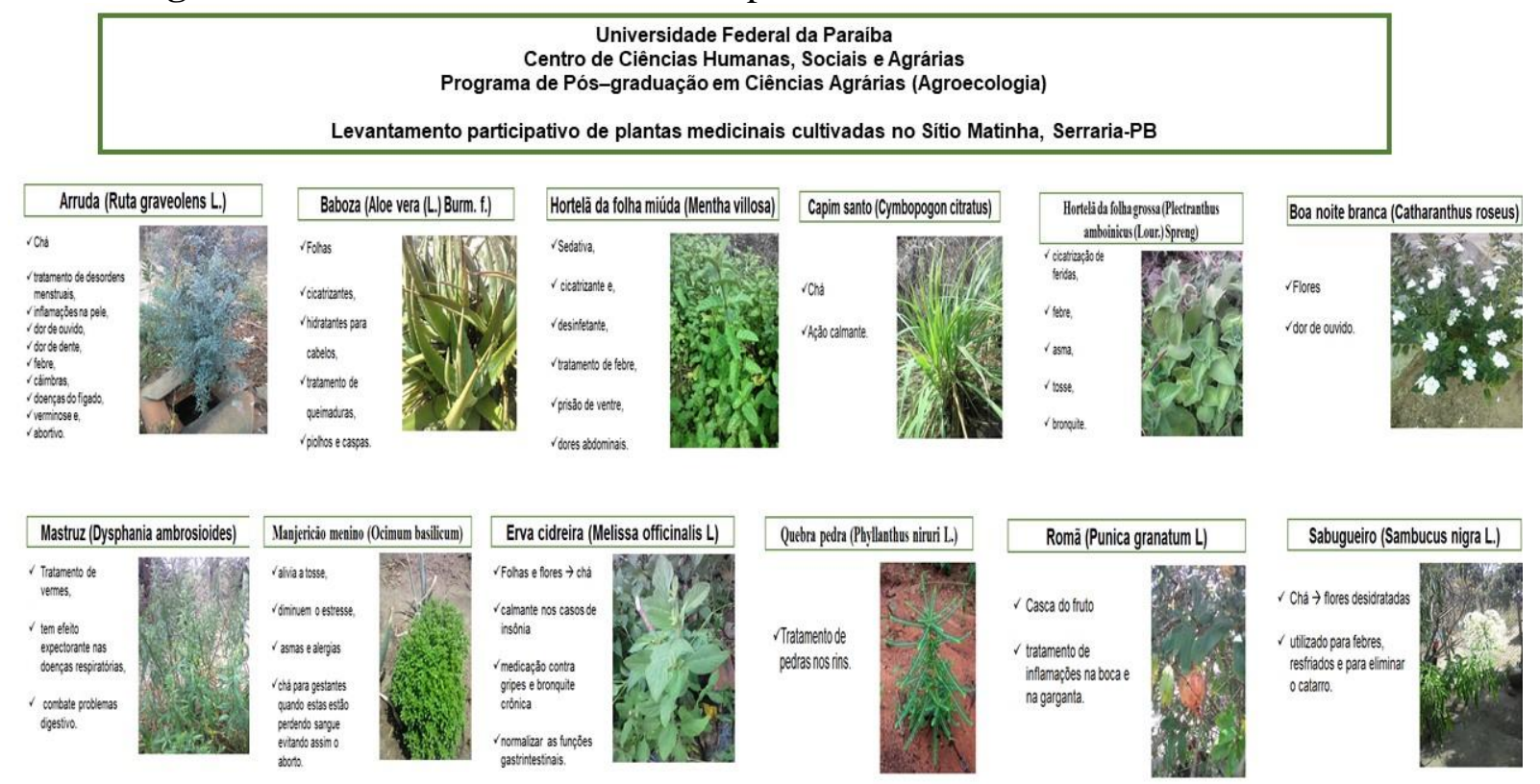

Fonte: Autor

Como parte integrante da pesquisa social, realizamos a socialização conteúdo aqui apresentado em uma oficina de produção de plantas medicinais, realizada no dia 13 de abril de 2018 das 8-12h00, no Projeto de Assentamento (PA) Campo Verde II. A atividade foi realizada na propriedade de Dona Ivonete e Senhor Arnaldo, produtores agroecológicos que fazem parte do Organismo de Controle Social (OCS) da Associação da Feira da Agricultura Familiar de Serraria-PB, Cadastrada no Ministério da Agricultura, Pecuária e Abastecimento como, autorizada assim, para venda direta de alimentos orgânicos.

O público atendido foi composto por agricultores, agricultoras e jovens agricultores familiares integrantes da OCS supracitada e membros de uma equipe que se propõe à produção e comercialização de flores no referido município, totalizando 24 participantes de diversas localidades do município: Sítio Saboeiro, Sítio Matinhas, Sítio Salamandra, PA Campo Verde II, PA Cajazeiras e centro urbano, o que enriqueceu a dinâmica social ofertando mais conhecimento a todos os presentes.

Os facilitadores da atividade, mestrandos que atuaram na pesquisa social aqui descrita, basearam-se no saber coletivo e participativo para realização da mesma, sendo assim, todos os presentes foram responsáveis pela partilha do conhecimento, o que resultou em um ambiente diverso e rico em saberes.

A maior parte das plantas medicinais se propaga a partir de sementes ou estacas. $\mathrm{Na}$ referida atividade com os agricultores realizou-se a produção de mudas a partir da estaquia 

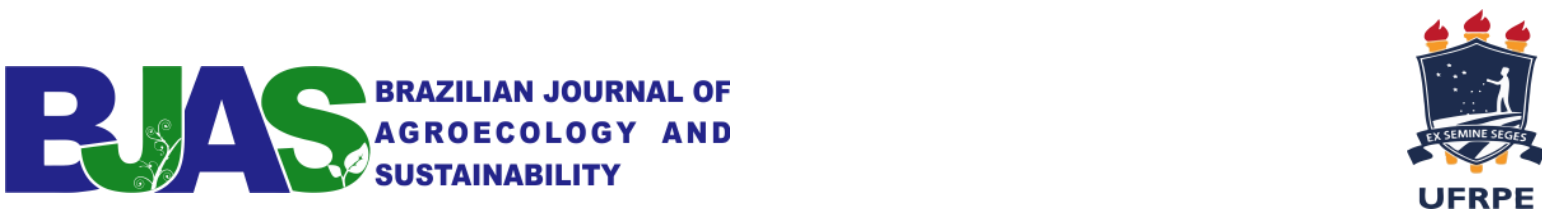

(figura 14) em sacos de polietilenos (figura 15) com um composto (figura 16) de terra vegetal esterco bovino na proporção de $3 \mathrm{X} 1$ preparado junto com os agricultores. Tanto o esterco quando a terra vegetal, foram obtidos na propriedade onde realizava-se a oficina.

Figura 14: Material vegetativo para produção das mudas de plantas medicinais.

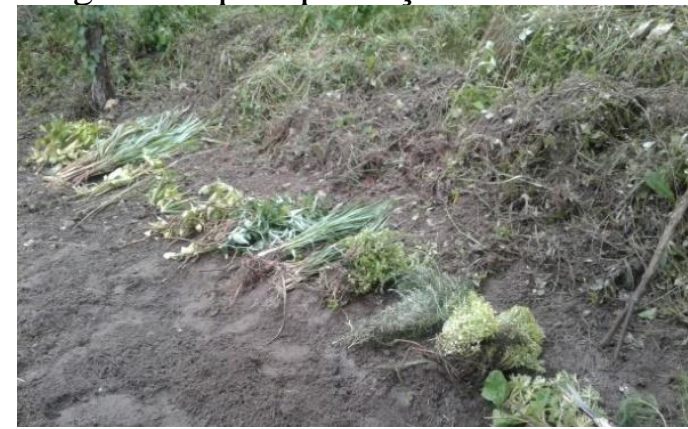

Fonte: arquivo pessoal.

Figura 15: Preparo dos saquinhos para recebimentos das estacas de plantas medicinais.

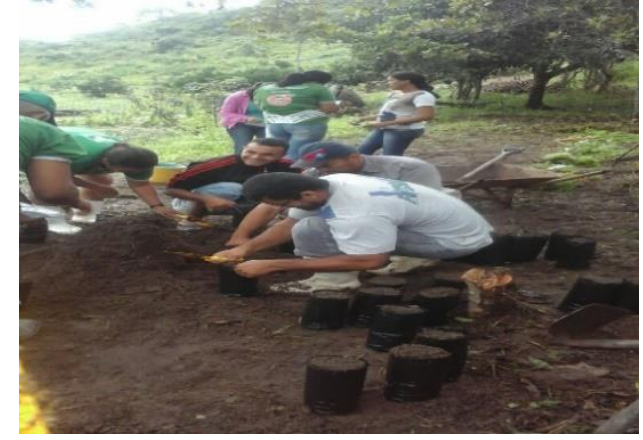

Fonte: arquivo pessoal.

Figura 16: Composto utilizado (terra vegetal + esterco bovino) na produção das mudas.

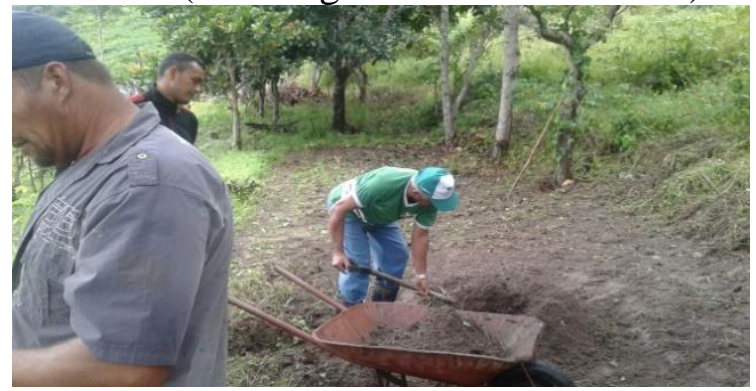

Fonte: arquivo pessoal.

Além das plantas medicinais identificadas, realizou a multiplicação das culturas mais utilizadas na região para chá, lambedouros, cicratização, dentre outras, conforme a tabela 1. 

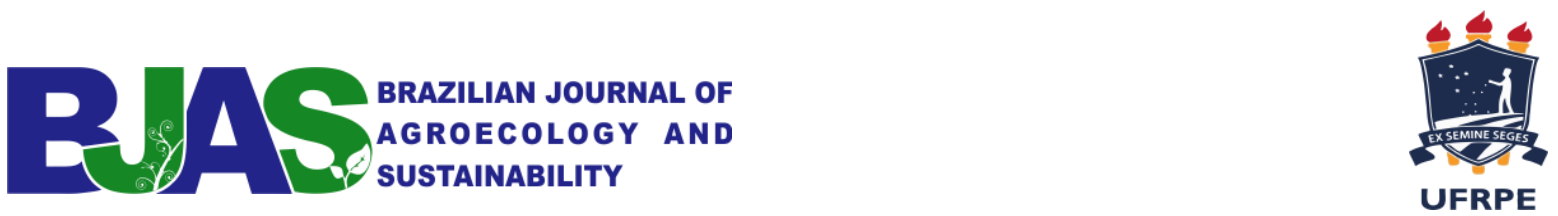

Tabela 1: Plantas medicinais partilhadas pelos agricultores (as) para multiplicação na oficina de produção de plantas medicinais no dia 13 de abril de 2018 no PA Campo Verde II.

\begin{tabular}{|c|c|}
\hline Cultivar & Utilização \\
\hline $\begin{array}{l}\text { Agrião } \quad \text { (Nasturtium } \\
\text { officinale } \\
\text { R. Br.) }\end{array}$ & $\begin{array}{l}\text { Popularmente utilizado como anti-inflamatório, para tosses e bronquites. Utiliza- } \\
\text { se as folhas e os ramos verdes para o preparo do lambedor, preferencialmente } \\
\text { com mel de abelha uruçu. }\end{array}$ \\
\hline $\begin{array}{l}\text { Alecrim (Rosmarinus } \\
\text { officinalis L.) }\end{array}$ & $\begin{array}{l}\text { Suas folhas secas e partes florais são utilizadas como diurético, sedativo e para o } \\
\text { tratamento da caspa e queda de cabelo, de acordo com falas dos agricultores } \\
\text { presentes na atividade. }\end{array}$ \\
\hline $\begin{array}{ll}\text { Boldo } & \text { nacional } \\
\text { (Plectranthus } & \text { barbatus } \\
\text { Andrews) } & \\
\end{array}$ & $\begin{array}{l}\text { Também conhecido como falso boldo, suas folhas são usadas para tratamento } \\
\text { alternativo de doenças hipotensoras, cardioativa, antisséptica, calmante e } \\
\text { antirreumática. }\end{array}$ \\
\hline $\begin{array}{l}\text { Citronela (Cymbopogon } \\
\text { nardus L.) }\end{array}$ & $\begin{array}{l}\text { Utilizada na região como repelente para insetos, aromatizadora, bactericida e } \\
\text { calmante, sendo muito utilizada na confecção de cosméticos. }\end{array}$ \\
\hline $\begin{array}{l}\text { Erva doce (Pimpinella } \\
\text { anisum L.) }\end{array}$ & $\begin{array}{l}\text { Muito utilizada no combate à má digestão, gases, dor de barriga ou artrite, ou } \\
\text { simplesmente como chá calmante. }\end{array}$ \\
\hline Louro (Laurus nobilis L.) & Utilizado como relaxante muscular, pois alivia dores e contusões. \\
\hline $\begin{array}{l}\text { Manjericão } \\
\text { basilicum L.) }\end{array}$ & $\begin{array}{l}\text { Mais utilizado, na região, para o combate a tosse, febre, feridas, infecções na } \\
\text { garganta e intestino. As folhas são utilizadas para o chá. }\end{array}$ \\
\hline $\begin{array}{l}\text { Saião } \quad \text { (Kalanchoe } \\
\text { brasiliensis Cambess })\end{array}$ & $\begin{array}{l}\text { Utilizada no tratamento de alterações estomacais, como indigestão ou dor de } \\
\text { estômago, tendo, também, efeitos anti-inflamatório, antimicrobiano, anti- } \\
\text { hipertensivo e cicatrizante. }\end{array}$ \\
\hline
\end{tabular}

Além das plantas medicinais citadas anteriormente também foram produzidas mudas (figura 17) das que foram identificadas no levantamento participativo, contudo, também foi abordada outras plantas como finalidades medicinais que não estavam disponíveis para a produção de mudas, tais como o abacateiro, o coco catolé, a casca do caule do cajueiro vermelho, dentre outras.

Figura 17: Mudas de plantas medicinais produzidas na oficina no PA Campo Verde II.

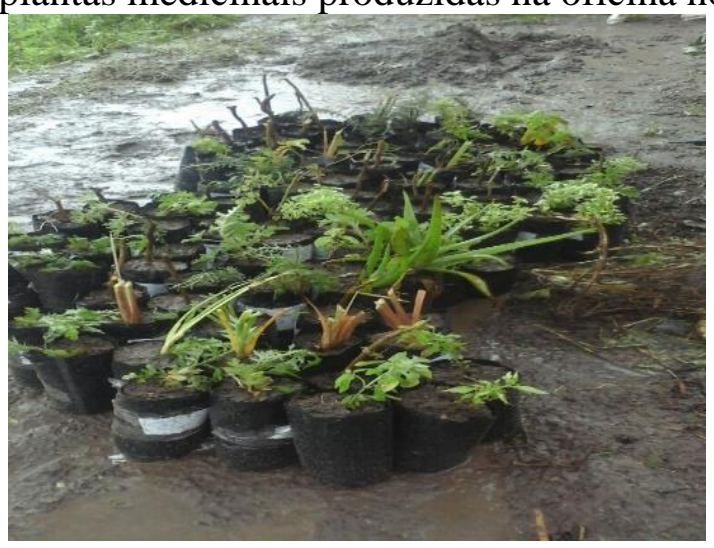

Fonte: arquivo pessoal.

Toda atividade foi realizada de maneira participativa (figura 18), onde todos puderam participar de todas as etapas da oficina, descritas a seguir, além de sugerirem aprimoramentos 

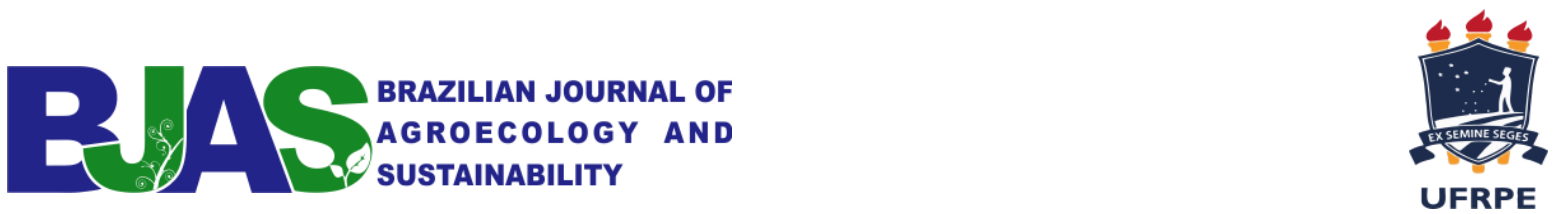

e partilharem os saberes sobre as culturas trabalhadas, trazendo os agricultores não apenas como meros expectadores da oficina, mas como protagonistas das ações desenvolvidas.

1. Apresentação dos participantes com uma dinâmica de boas-vindas, e, apresentação do objetivo da oficina;

2. Partilha e separação do material vegetativo de plantas medicinais trazidos pelos agricultores e estudantes;

3. Identificação de cada espécie partilhada;

4. Higienização dos materiais vegetativos e utensílios a serem utilizados para produção das estacas;

5. Atividade coletiva de identificação da utilização das plantas com fins medicinais (nessa etapa foram confeccionadas tarjas para identificação de cada cultura em seu referido saquinho, com algumas de suas utilizações);

6. Preparo do composto;

7. Enchimento dos saquinhos;

8. Plantio das estacas com rega natural, pois neste momento estava chovendo;

9. Avaliação da atividade.

Figura 18: Atividades coletivas na oficina de produção de mudas de plantas medicinais.

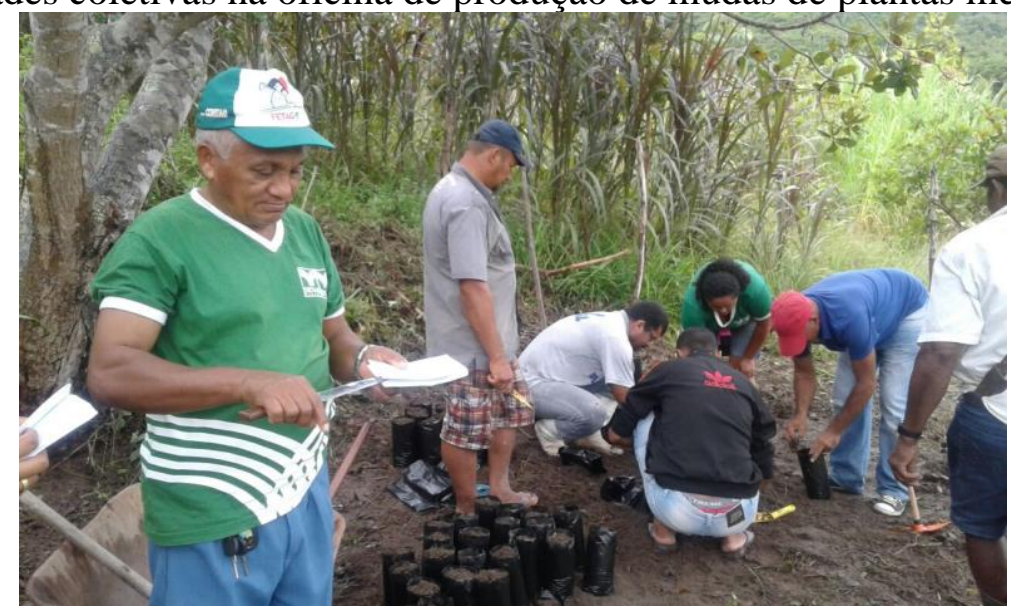

Fonte: arquivo pessoal.

Após o enraizamento das mudas, estas poderão ser transplantadas para canteiros, jardins, covas ou sulcos, além de vasos, ou mesmo comercializadas nos próprios saquinhos. Vale salientar que o cultivo de algumas plantas medicinais em canteiros de hortas, por exemplo, possibilita o controle de alguns insetos e lagartas, uma vez que estas, em sua grande maioria, têm aroma forte e liberam alguns princípios ativos que funcionam como repelentes naturais. 


\section{CONSIDERAÇÕES FINAIS}

As plantas medicinais se constituem em uma importante estratégia para as famílias rurais no que diz respeito à economia na aquisição de remédios, podendo ser uma fonte de renda extra quando comercializado em feiras.

Um dos maiores benefícios das plantas medicinais para os agricultores é a acessibilidade em seus quintais e hortas, a toda hora, sem gastos adicionais.

O resgate, valorização e manutenção dessas culturas se fazem muito importantes, uma vez que geram autonomia para as famílias e valorização das experiências e conhecimentos populares dos agricultores.

A formação continuada foi muito importante, pois, mostrou aos agricultores do município que o uso de plantas medicinais em substituição de medicamentos convencionais e muito eficaz.

\section{REFERÊNCIAS}

Agência Nacional de Vigilância Sanitária. (2004). Resolução RDC n 48, de 16 de março de 2004. Dispõe sobre o registro de medicamentos fitoterápicos. 2 - Accorsi WR. Medicina natural, um novo conceito. A fórmula: guia de negócios, 2(4), 5.

Arnous, A. H, Santos A. S, \& Beinner, R. P. C. (2005, jun.). Plantas medicinais de uso caseiro: conhecimento popular e interesse por cultivo comunitário. Revista Espaço para a Saúde, Londrina, 6(2), 1-6.

Berg, M. E. van den. (1987). Plantas medicinais da Amazônia: contribuição ao seu conhecimento sistemático. Belém: Museu Paraense Emílio Goeldi.

Instituto Brasileiro de Geografia e Estatística (Org.). (2018). Infográficos: dados gerais do município. Recuperado de https://cidades.ibge.gov.br/brasil/pb/serraria/panorama.

Lameira, O. A \& Pinto, J. E. B. P. (2008). Plantas medicinais: do cultivo, manipulação e uso à recomendação popular. Belém: Embrapa Amazônia Oriental.

Matos, F. J. A. (1987). O formulário fitoterápico do professor Dias da Rocha (ESAM. Coleção Mossoroense, 365). Mossoró: Escola Superior de Agricultura de Mossoró.

Nogueira, M. J. C. (1983). Fitoterapia popular e enfermagem comunitária. Rev Esc Enf-USP, 17(3), 275.

Pimentel, A. A. M. P. (1994). Cultivo de plantas medicinais na Amazônia (114 p.). Belém: FCAP. 


\section{AGRADECIMENTOS}

Agradecemos aos agricultores familiares que participaram da construção desse trabalho de maneira participativa e colaborativa, ambos resides nos Sítio Matinhas, Saboeiro, Salamandra e PA's Campo verde II e Cajazeiras, zona rural do município de Serraria-PB e participantes da Feira da Agricultura Familiar de Serraria-PB, além dos residentes da cidade que fazem parte junto com os agricultores da equipe de produção e comercialização de flores. Que a cada dia tenham a força e determinação necessária para seguirem nessa bela missão do cuidar da terra e da natureza. 